Document downloaded from:

http://hdl.handle.net/10251/148865

This paper must be cited as:

Galindo, J.; Tiseira, AO.; Navarro, R.; Tarí, D.; Meano, CM. (2017). Effect of the inlet geometry on performance, surge margin and noise emission of an automotive turbocharger compressor. Applied Thermal Engineering. 110:875-882.

https://doi.org/10.1016/j.applthermaleng.2016.08.099

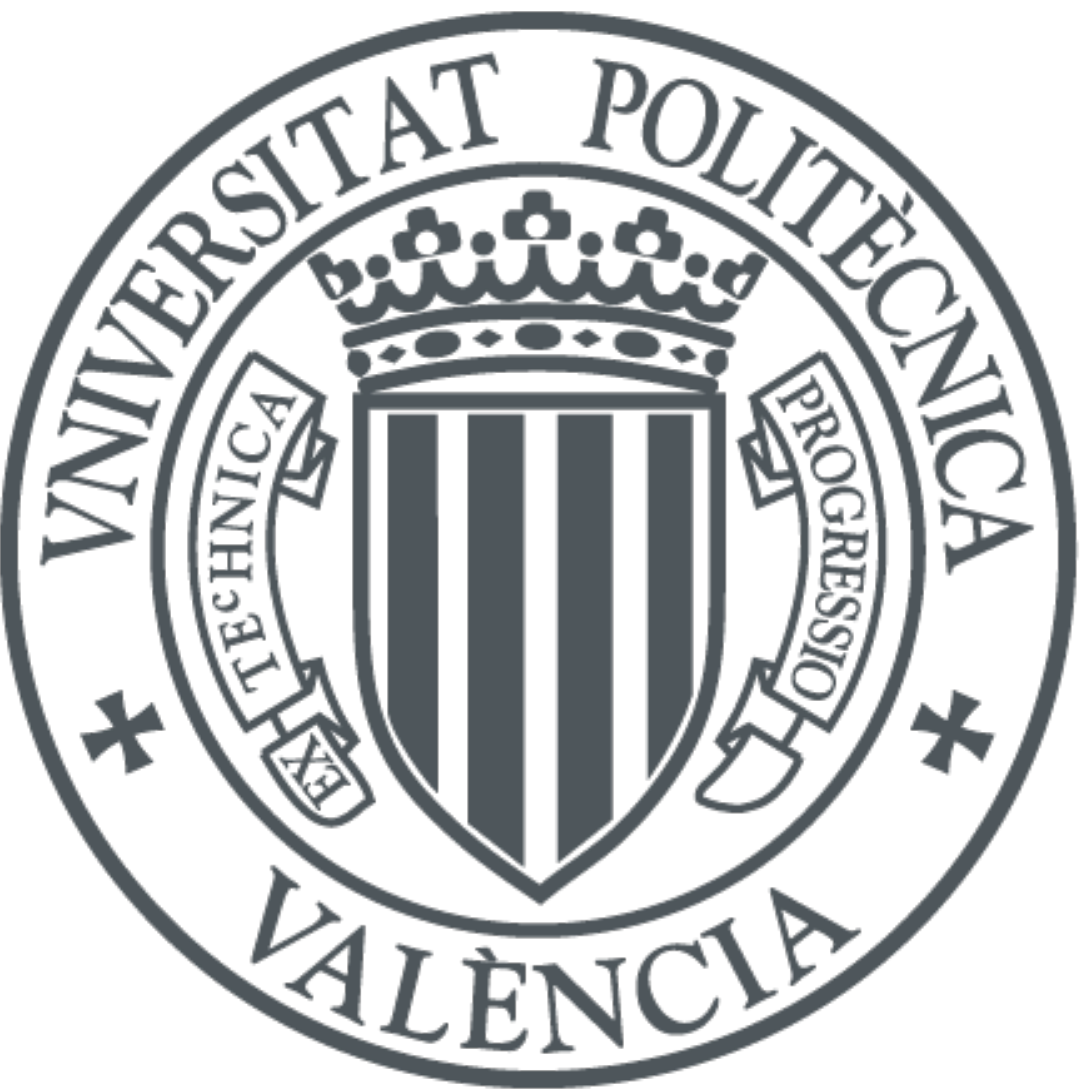

The final publication is available at

https://doi.org/10.1016/j.applthermaleng.2016.08.099

Copyright Elsevier

Additional Information 


\section{NOTICE:}

this is the author's version of a work that was accepted for publication in Applied Thermal Engineering. Changes resulting from the publishing process, such as peer review, editing, corrections, structural formatting, and other quality control mechanisms may not be reflected in this document. Changes may have been made to this work since it was submitted for publication. A definitive version was subsequently published as:

J. Galindo, A. Tiseira, R. Navarro, D. Tarí, C. Meano, Effect of the inlet geometry on performance, surge margin and noise emission of an automotive turbocharger compressor, Applied Thermal Engineering 110 (2017) 875-882. doi:10.1016/j.applthermaleng.2016.08.099 


\title{
Effect of the inlet geometry on performance, surge margin and noise emission of an automotive turbocharger compressor
}

\author{
J. Galindo ${ }^{\mathrm{a}}$, A. Tiseira ${ }^{\mathrm{a}}$, R. Navarro ${ }^{\mathrm{a}}$, D. Taría,*, C.M. Meano ${ }^{\mathrm{b}}$ \\ ${ }^{a}$ CMT - Motores Térmicos, Universitat Politècnica de València \\ Camino de Vera, 46022 Valencia \\ ${ }^{b}$ GM Global Propulsion Systems-Torino Srl Corso Castelfidardo 36 - 10129 Torino (I)
}

\begin{abstract}
Centrifugal compressor performance at low mass flow rates has become an issue in the latest years due to engine downsizing and the increase of low-end torque request. The principal drawback of this operating region is the appearance of the surge phenomenon, which is strongly affected by the compressor inlet geometry. This work is addressed to study the impact of different inlet geometries on the compressor performance, including compressor efficiency, noise emission and surge margin. An engine test bench is set up with a centrifugal compressor and both steady and transient (tip-out) tests are performed in order to obtain a complete view of the influence of each configuration. The results show a clear sensitivity of the compressor parameters to the variations of the geometry upstream the compressor inlet. Keywords: Engine test bench, Tapered duct, Nozzle, Tip-out test
\end{abstract}

*Corresponding author. Tel.: +34 963877650

Email addresses: galindo@mot.upv.es (J. Galindo), anti1@mot.upv.es (A. Tiseira), ronagar1@mot.upv .es (R. Navarro), datade@mot.upv.es (D. Tarí), cesare.meano@gm.com (C.M. Meano) 


\section{Introduction and literature review}

Turbochargers (TC) are well known machines with a development of near a hundred years. However, the application of turbomachinery to reciprocating internal combustion engines (ICEs) is relatively new, experimenting a notable increase in the last fifteen years for diesel engines and even less for gasoline engines. Thus, there is still room for further studies of the couple TC-ICE. The study of this combination is particularly relevant due to the trend that most engines are following, the downsizing, which is the tendency of reducing the total cylinder displacement. Turbocharging is really interesting when using this approach, because it helps achieving higher specific power and efficiency.

Nevertheless, a turbocharged engine presents some drawbacks due to the coupling between two different machines. On one hand, the four stroke ICE is a reciprocating machine that performs its thermodynamic cycle in four piston strokes, generating acoustic pulses that propagate through the pipes arriving and interacting with the compressor and the turbine. Its rotational velocity varies from about 800 to $5000 \mathrm{rpm}$ in common situations. On the other hand, the turbocharger is a continuous flow machine which axis rotates at very high revolutions per minute (50k to $200 \mathrm{k}$ depending on the size). In addition, the TC responds to mass flow rate variations with a reduced rate of change of shaft speed due to the TC rotational inertia, among other factors. The mismatch between the dynamics of the engine and the turbocharger introduces what is called turbo-lag, which consists of a delay of the turbocharger response to engine demands.

Compressor working range is limited by choke conditions at very high 
mass flow rates. Wheel structural integrity also constrains maximum rotating speed. At low mass flow rates the compressor flow is not capable of overcoming the adverse pressure gradient due to its reduced velocity, and reversed flow appears. This produces a drop in compression ratio until the flow goes in the right direction, the pressure ratio increases and the cycle starts again. This is clearly an oscillating phenomenon, which introduces undesirable acoustics pulsations to the pipes. Moreover, axial loads appear, forcing the wheel against the walls and potentially causing mechanical damage [1]. This phenomenon is the so-called surge, which is described as a pulsating and transversally uniform phenomenon that affects mainly the compressor inlet [2]. This paper is devoted to the reduction of the impact of surge occurrence in actual engine operating conditions.

The research on compressor surge is addressed from different points of views. Some researches $[3,4,5]$ describe the possibility of finding different types of surge depending on the pulsation frequency and its amplitude. Other consider the attenuation or delay of appearance of the phenomenon thanks to control systems placed either upstream or downstream the compressor $[6,7,8]$. Some authors obtain a clear shift of the surge margin $[9,10]$. The margin can be improved or worsened depending on the element placed at the compressor inlet or outlet $[11,12,13]$.

Car manufacturers may have packaging constraints that result in different compressor intake geometries which have an impact on compressor performance that is not known beforehand [14, 15]. The effect of particular compressor intake geometries (elbow, tapered duct, reservoir, etc.) has been previously covered by several researchers $[16,17,18]$. However, they do not 
usually include the effect of the inlet pipe on compressor acoustic behavior. Turbocharger airborne noise is becoming a major issue for automotive industry because downsizing moves the compressor working zone closer to near-surge conditions [19, 20], at which whoosh noise appears [21]. 3D-CFD simulations provide satisfactory predictions of compressor acoustic signature [22], but the computational effort is so high that only a few operating conditions can be calculated.

Karim et al. [23] performed Large Eddy Simulations with 5 different inlet configurations (using swirl vanes, short and large steps and combinations of these elements) at two different operating conditions. The Sound Pressure Level (SPL) integrated over 6-12 kHz obtained at the compressor inlet is compared for the different inlet configurations. The combination of a large step with swirl vanes provides less SPL for both operating conditions. Experimental measurements with short and large step are performed in a powertrain dynamometer semi-anechoic cell. The SPL integrated between 4 and 12.7 $\mathrm{kHz}$ using radiated noise measurements shows the superior performance of the large step over the small step.

Compressors are generally tested in a test bench specially designed to obtain the centrifugal compressor map. Those tests are done in special conditions, such as large pipes and continuous flow [24]. But when the turbocharger is installed in the engine, the conditions are very different, with pulsating flow and short pipes, which affects the surge margin [25, 26].

Previous works show that inlet geometry has a major impact on surge, but the effect on other compressor parameters is not often considered. Moreover, not all relevant geometries have been covered and those which have been 
analyzed are often tested with steady working points that do not resemble their actual operating conditions. In this work, an automotive turbocharger is tested on its real engine so as to assess the actual effect of different inlet geometries on compressor performance, surge margin and noise emission.

The main disadvantage of the selected approach is the inability to perform detailed measurements at the compressor inlet. This information could be used to explain the flow behavior with the different intake configurations and thus the physical phenomena responsible for the modification of compressor performance when varying the inlet pipe. Raitor and Neise [27] were able to instrument a 224-mm-diameter compressor working at a steady rig with pressure transducers, but the procedure is more than challenging for the considered passenger car turbocharger compressor installed on an engine test bench, due to spatial constraints. Another possibility could be to perform Particle Image Velocimetry (PIV) measurements at the compressor entry, such as the campaign conducted by Guillou et al. [28]. The different shapes of the intake geometries and the reduced dimensions of the turbocharger again restrict this approach; for instance, Guillou et al. mounted a bell mouth at the compressor inlet.

In this paper, Section 2 describes the experimental apparatus, the tests performed and the different inlet configurations. The results of both steady and transient tests are shown in Section 3, whereas the conclusions of the paper are presented in Section 4. 


\section{Materials and methods}

\subsection{Experimental facility}

Tests were performed using a commercial engine in a test bench, allowing the compressor to achieve high loads and speeds. In addition, the compressor map that can be obtained with this set up may have some variations due to the particular matching with the engine, yielding a more realistic result. Engine main characteristics are listed below.

- Displacement: 2L.

- Number of cylinders: 4 .

- Fuel type: Diesel.

- Maximum power: $120 \mathrm{~kW}$ (163 hp) @ $3600 \mathrm{rpm}$.

- Maximum torque: 340 Nm @ 2000 rpm.

- Injection: common rail direct injection.

- Valve system: DOHC, 16 valves.

- Turbocharger with Variable Geometry Turbine (VGT).

Figure 1 depicts a schematic of the test bench, including all the sensors with which the rig was instrumented. A dynamo-metric brake was used, which controlled the engine speed and its torque. Almost all variables were registered at a frequency of $100 \mathrm{~Hz}$. Mass flow rate and compressor inlet pressure were recorded at a frequency of $1 \mathrm{kHz}$ instead, since they were used 
to detect surge appearance (see Section 2.2). Additionally, a directional intensity probe was installed facing the inlet mouth, surrounded by acoustic insulation mats in order to avoid reflections from the walls or other components [29]. This probe measures the sound intensity level (SIL) up to $5 \mathrm{kHz}$ in order to characterize the compressor intake orifice noise.

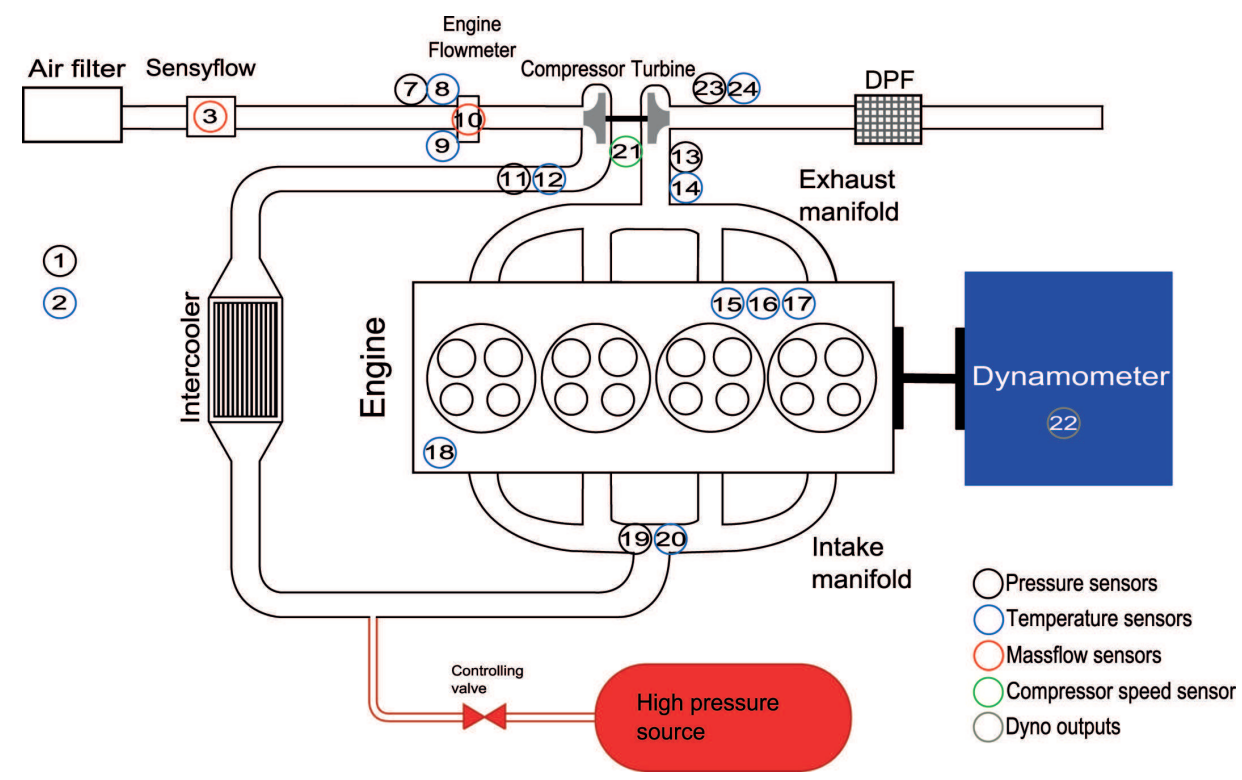

Figure 1: Test bench scheme

\subsection{Steady tests}

Different tests were performed with each inlet configuration in order to obtain the compressor behavior in both steady and transient operating conditions. First, steady tests include the characterization of the surge line, what is done injecting compressed air in the inlet manifold [30, 31]. An air compressor from the workshop provides the test cell with high pressure air, which is connected to the inlet manifold through a controlled pneumatic 
valve. With this method, the injected air enters in the cylinders and consequently, less air passes through the compressor, which is controlled indirectly by the VGT position, forcing it to keep the pressure ratio constant. It is possible to perform this action thanks to the open ECU available in the engine. In this way the compressor operating point moves towards the surge limit until suddenly it becomes unstable and enters in deep surge. At this moment, the air injection is stopped so that the compressor does not suffer any damage. The last stable point, obtained by a frequency analysis over the instantaneous pressure recording [26], determines the surge limit and, if this process is repeated for different compression ratios, the surge line can be determined by joining these points.

The second steady-state test consists in obtaining part of the compressor map itself; from the surge line to medium mass flow rates. It is not objective of this study to obtain the complete compressor map. The process followed in this case is very similar to the surge line method. Firstly, a compression ratio is imposed by controlling the VGT; the air injector valve is closed at the beginning and gets open progressively. For a certain valve position, the engine will eventually reach a steady-state working point, and then the acquisition systems get data from the sensors during five seconds in order to get a mean value. Afterwards, the compression ratio is changed and the process is repeated.

For every measured working point, two important parameters are calculated. One of them is the SIL, which is obtained from the intensity probe described in Section 2.1. The other one is the compressor isentropic efficiency, 
which is defined by:

$$
\eta_{c}=\frac{\left(\frac{p_{\text {out }}}{p_{\text {in }}}\right)^{\frac{\gamma-1}{\gamma}}-1}{\frac{T_{\text {out }}}{T_{\text {in }}}-1},
$$

where $\gamma$ is the ratio of specific heats.

The last steady test is the obtaining of the $160 \mathrm{krpm}$ turbocharger isospeed line, which is used to have an estimation of the pressure drop of each inlet configuration at high air mass flow rates. Turbocharger speed is kept constant actuating over the VGT position.

\subsection{Transient tests}

In Section 1 the lag problem of the turbocharger was introduced. This issue may lead the TC into surge, as graphically explained by Fig. 2, where two processes are depicted. In the left one, an engine acceleration from point 1 to point 2 is plotted. If the evolution was quasi-steady, the path would be a straight line between these two points. Due to the turbo lag, there is an increase of the mass flow followed by an increase of the compression ratio, though. On the right hand side of Fig. 2, an engine deceleration from point 1 to point 2 is depicted. In this case, the compressor operation deviates from the straight path reducing the mass flow in first place and then reducing compressor pressure ratio. Stability problems may appear under this condition, since a sudden reduction of the mass flow when the starting point presents low mass flow rates can drive the compressor beyond the surge line.

Transient tests aim to reproduce the aforementioned problem by performing sudden pedal releases at different boosting pressure, engine speed and engine decelerating rate. These tip-out experiments are of importance 

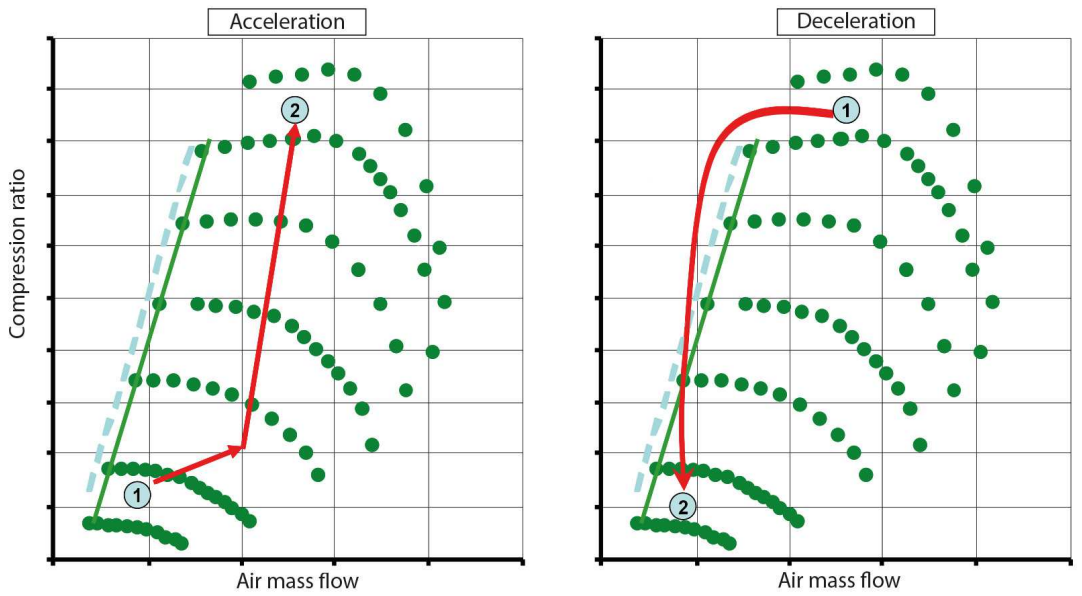

Figure 2: Acceleration and deceleration transient evolutions over a compressor map

because they reproduce the onset of surge in real driving conditions. However, they are scarcely used in the literature, save for papers dealing with the design of surge control systems [32, 33].

In this work, boosting pressures tested varied from 1.2 to 2.4 bar, engine regimes covered a range from 1250 to $2250 \mathrm{rpm}$ and deceleration rates were imposed to go from 200 to $1200 \mathrm{rpm} / \mathrm{s}$. Due to the compressor map topology, not every combination of boosting pressure and engine speed could be achieved, neither some points were able to reach surge conditions because of being too far from this zone. Each test was repeated three times in order to obtain averaged values. Data acquisition in these tests was performed by the high frequency acquisition system, which is able to register variables at $1 \mathrm{kHz}$, enough to get surge oscillations. Only engine speed, pedal position, mass flow, compressor outlet pressure and turbocharger speed sensors were connected to this system due to the high size of the generated files.

An example of a tip-out test is depicted in Fig. 3.a. When a sudden pedal 
release is produced, the compressor behavior becomes unstable, entering in and out of surge until the compression ratio is low enough to recover the stability (see Fig. 3.b). Thus, the number of oscillations is a good indicator of the surge severity. In order to count the number of surge cycles, the compressor outlet pressure is derived and the local maximums are counted with the aid of a computational tool (Fig. 3.c). The final number of cycles is the average value between the three repetitions of the same experiment. The maximum rate of pressure change (bar/s) during the surge cycles was also used to evaluate the harm caused by this phenomenon, since this parameter is related with the intensity of the axial strokes that the turbocharger bearing should deal with. Finally, the characteristic frequency of the surge cycles is calculated with a Fourier analysis.

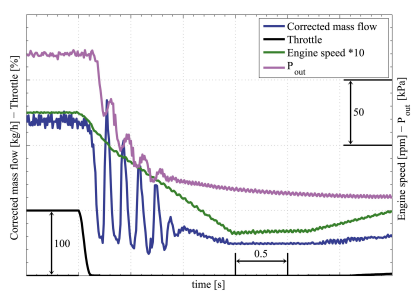

(a) pedal release variable evolution

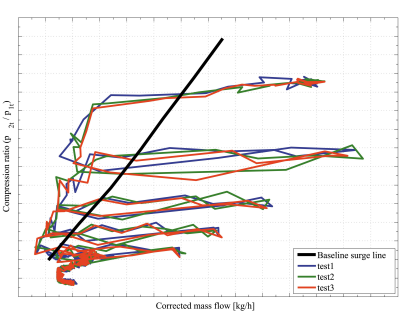

(b) transient evolution over ( the compressor map

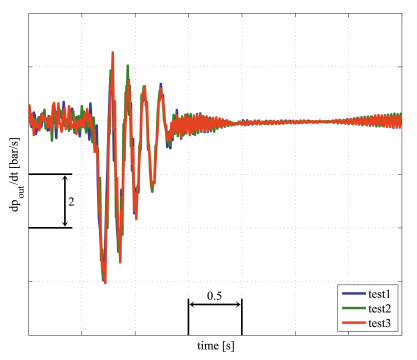

(c) Derivative of the boosting pressure

Figure 3: Variable evolution during a sudden pedal release in both ducts

\subsection{Compressor housing preparation}

Since different inlet geometries are tested with the same compressor, the latter needs to be modified in order to allocate all the configurations. This modification consists in drilling the inlet until $3 \mathrm{~mm}$ of the inducer are left 
uncovered. Also two aluminum blocks are welded on both sides of the volute to be used as brackets. Figure 4 depicts the final state of the compressor housing. The left hand side of the figure displays the modified volute with the inducer housing removed and the support aluminum blocks. On the right hand side of the figure it is shown the piece whose function is to join the compressor with the different configurations. In this piece an orifice is drilled where the compressor speed sensor is placed. A groove in its edge hosts an O-ring which seals the junction between both pieces.

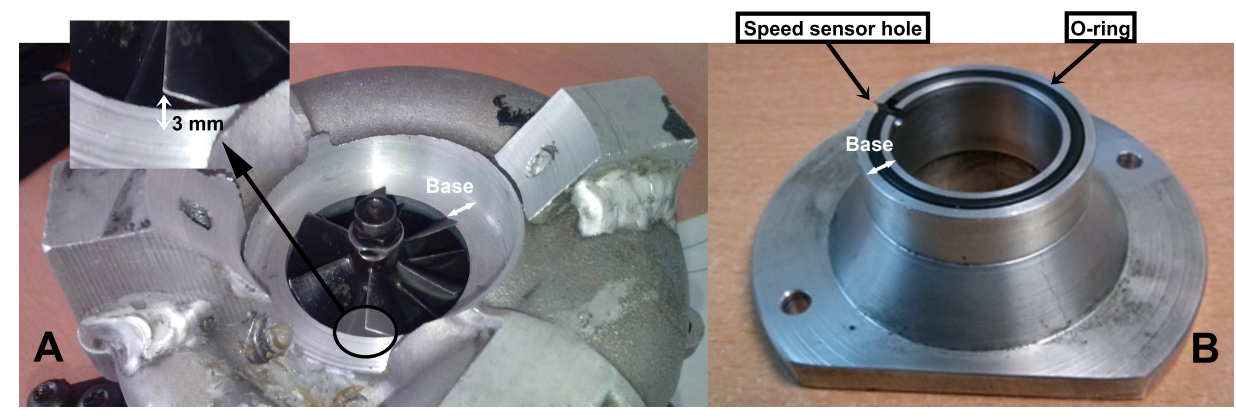

Figure 4: A) Modified compressor housing, B) Coupling piece

\subsection{Inlet configuration}

In section 1 several intake geometries that may be considered (elbow, tapered duct, reservoir, etc.) were appointed. To decide which of them are more interesting to be investigated, a Pugh matrix was done in the following manner. In first place, important features of each mechanism are considered, such as complexity, scalability, noise emission or global performance. Then, each feature of each configuration is preliminarily evaluated and given a score from 0 to 5. Finally, scores are counted, high scores meaning interesting configurations. This step ended with the tapered duct and the nozzle as 
the chosen geometries. An additional geometry is considered as a baseline to assess the impact of each configuration. It consists in a straight pipe, just enlarging the compressor inlet with constant diameter long enough to assure developed flow at the inlet ( $>10$ Diameters). This baseline geometry is depicted in Fig. 5.a, where the inducer plane is also schematically represented. For future comparisons it will be treated as configuration a).

\subsubsection{Tapered duct}

A tapered duct consists in a progressive narrowing towards the compressor wheel. This narrowing can be more or less pronounced, the slope can be constant (straight) or variable (curved) and the joints can be angled or smooth. In this case, due to constructive restrictions, the tapered part is straight and the joints are quite angled. A $90^{\circ}$ semi-angle would represent the sudden expansion of a reservoir, device which provides a significant surge margin improvement according to Lang [18]. However, a reduction in the angle should decrease the pressure drop introduced by the device. The schematic of this design can be noticed in Fig. 5.b, from now on, configuration b).

\subsubsection{Nozzle}

The other device chosen is the nozzle. Desantes et al. [34] obtained the compressor map of a turbocharger with a nozzle in its inlet. The nozzle was designed with a convergent-divergent shape optimized to minimize the pressure loss. The resulting compressor map had its surge line significantly shifted to the left and the efficiency was globally increased. The obvious drawback of this element is the limited maximum flow rate and important 
pressure losses when the operating point is near this limit. These losses are due to the near transonic conditions through the throat. The final design of the nozzle used is depicted in Fig. $5 \mathrm{C}$ (configuration c)).

\subsubsection{Final configurations}

Once the basic designs have been decided, the particular configurations that were actually mounted and tested were selected with the following considerations.

The baseline case (straight duct) required no additional information. Steady and transient test were performed with this configuration as a reference for subsequent comparisons.

Several distances of wheel-to-tapered duct were tested to obtain the surge line, and a complete test was therefore performed with the configuration with the best performance.

For the nozzle, another study of the surge margin sensitivity to the device position was performed, investigating now the distance from the wheel to the nozzle throat. Separators of different length were mounted between the device and the compressor and tested. Again, the particular distance that provided the best results was selected for the full experimental campaign. Additionally, the divergent part of the nozzle was removed, allowing the throat to discharge directly against the compressor wheel (see Fig. 5 D). A complete test with this last configuration was also conducted (configuration d)). 


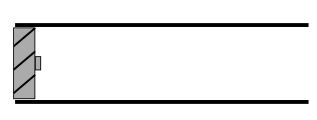

(a)

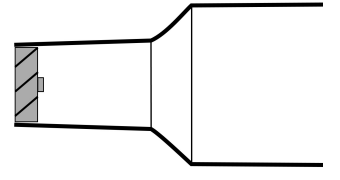

(b)

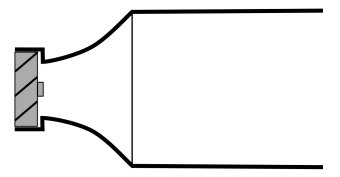

(d)

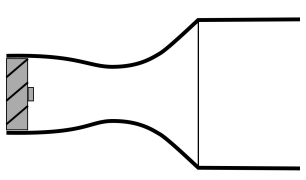

(c)

Figure 5: Configuration schemes

\section{Results}

\subsection{Steady results}

\subsubsection{Surge and $160 \mathrm{krpm}$ lines}

Steady tests were performed as described in Section 2.2, obtaining surge and $160 \mathrm{krpm}$ lines for the configurations selected in Section 2.5.3. Figure 6 depicts the corrected mass flow of the surge line (expressed relatively to the baseline configuration) at three different compression ratios.

Surge lines are significantly shifted to lower mass flow rates for all the configurations. The tapered duct and the convergent-divergent nozzle achieve a similar gain, which is kept through all the compressor pressure ratio range. However, the convergent nozzle increases the surge margin for higher pressure ratios even more. In Fig. 7 it is shown another histogram about the relative corrected mass flow at $160 \mathrm{krpm}$ and at the same compression ratio near choke conditions. This figure illustrates the important drawback of the convergent nozzle, which is its bad performance at high mass flow rates. This is due to the change in the relative position of the throat to the inducer. With 


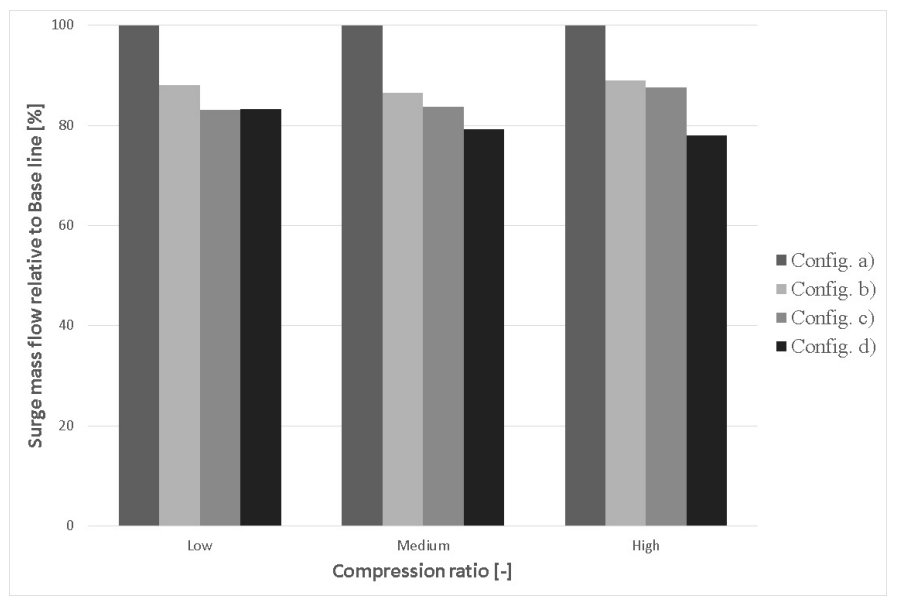

Figure 6: Surge improvement at different compression ratios

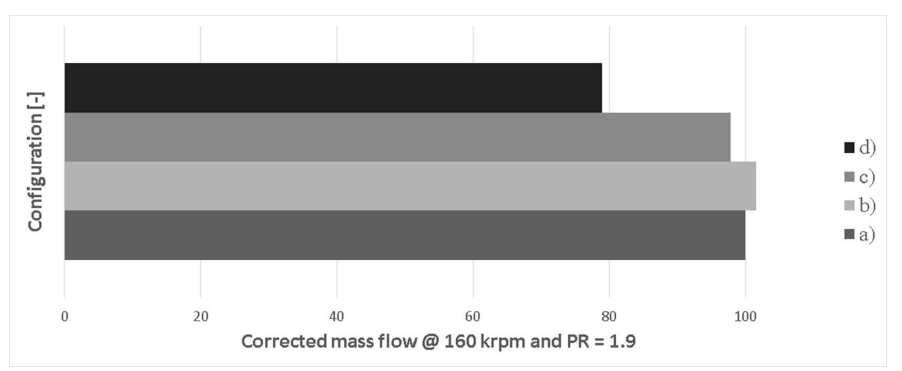

Figure 7: Corrected mass flow at $\Pi_{c}=1.9$ for $160 \mathrm{krpm}$ lines

the throat discharging directly to the wheel, the periphery of the inducer plane gets blocked, reducing the flow effective cross-section at the inducer plane. A similar effect would be obtained by reducing the compressor trim, what would decrease the maximum mass flow rate. On the contrary, the convergent-divergent nozzle provides a similar pressure drop compared with the straight duct because the inducer plane remains unblocked. Finally, the tapered duct slightly improves pressure ratio due to the inlet duct crosssection increase. 


\subsubsection{Compressor efficiency}

Using a computer tool, it is possible to interpolate the results of the points obtained during the steady test and plot isentropic efficiency (see Eq. 2.2) contours over a compressor map. Figure 8 depicts such map for the studied configurations. Green represents higher efficiencies and red lowers. The axes have been normalized using the following equations:

$$
\begin{gathered}
\hat{\dot{m}}^{*}=\frac{\dot{m}^{*}}{\dot{m}_{d}^{*}} \\
\hat{\Pi}_{c}=\frac{\Pi_{c}-1}{\Pi_{c, d}-1},
\end{gathered}
$$

where $\dot{m}_{d}^{*}$ and $\Pi_{c, d}$ correspond to a design operating point of the compressor with the baseline configuration.

The augmented surge margin of the tapered duct entails an increase of isentropic efficiency in the surge side of the compressor map for this configuration. The convergent-divergent nozzle seems to shift best efficiency point (BEP) towards a lower mass flow and compressor speed, with an efficiency enhancement near the surge line, particularly at low compressor speeds. The BEP shift to a reduced mass flow rate and compressor speed is clear for the case of the convergent nozzle. Although the efficiency near surge is improved compared to the baseline case, maximum efficiency is decreased and the rest of the compressor map (higher mass flows) presents an efficiency loss.

\subsubsection{Noise emission}

Figure 9 uses the same approach of Section 3.1.2 to plot the SIL map for the different configurations. SIL was calculated from 20 to $5000 \mathrm{~Hz}$ with 

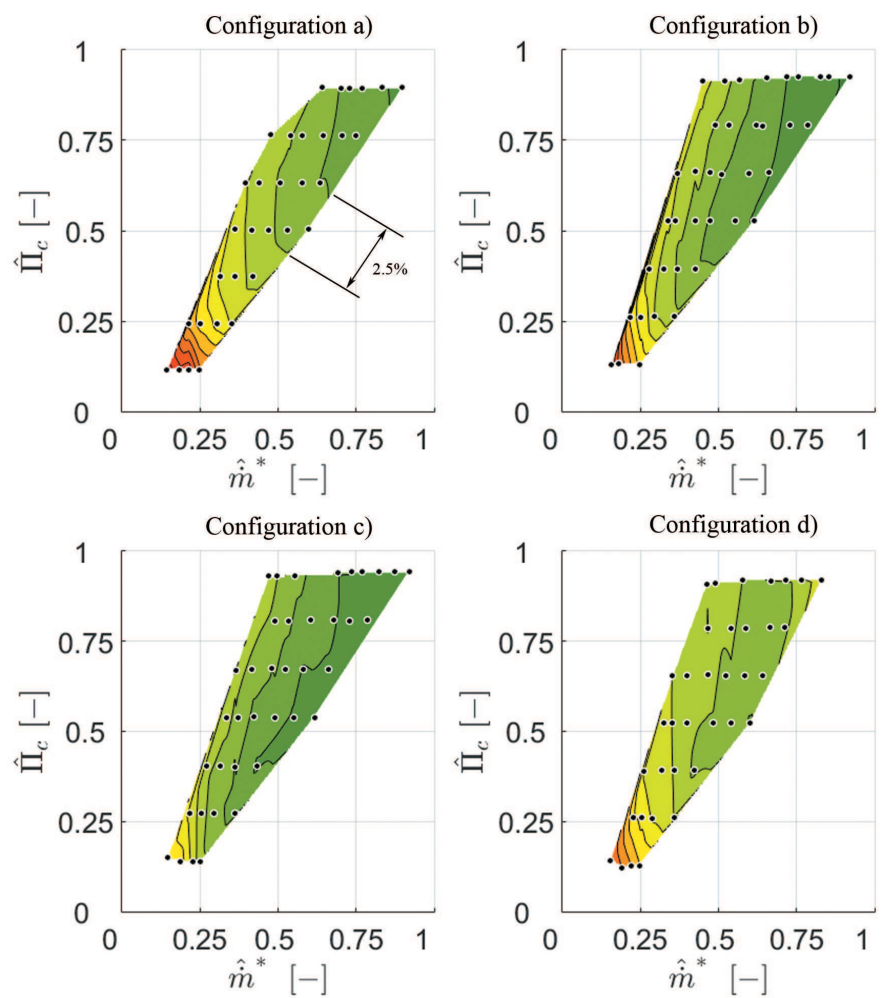

Figure 8: Compressor efficiency maps

the intensity probe described in Section 2.1. In this case, green colors mean softer noise and red represent louder noise. The axes have been normalized using equations (2) and (3).

Observing the figure, the tapered duct is slightly noisier than the convergentdivergent nozzle. This is due to the higher diameter of the tapered intake duct. As aforementioned, the reduction of the flow effective cross-section at the inducer plane caused by the convergent nozzle also reduces the area of the noise emission, lowering the measured intensity notably. 

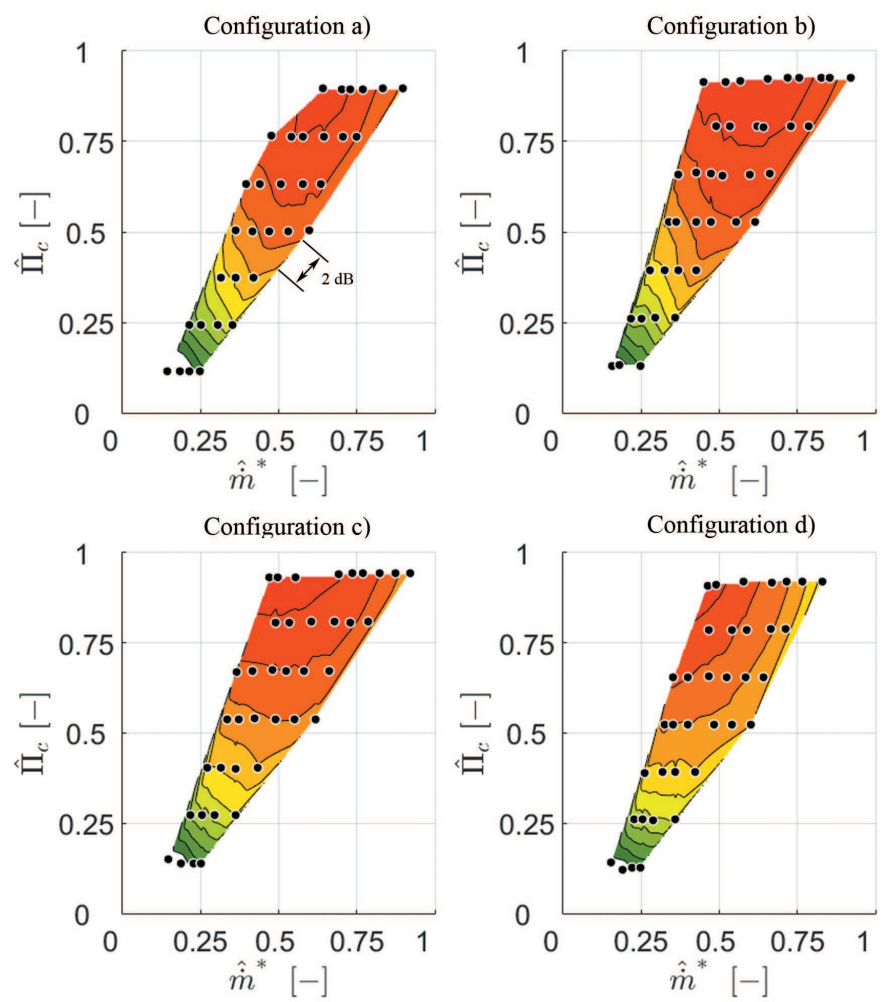

Figure 9: Compressor SIL maps

\subsection{Transient results}

The complete amount of data obtained during the transient tests described in Section 2.3 is quite extensive, so Table 1 presents a summary of these results. First column shows the percentage of the tip-out tests at which surge occurred for each configuration. The average number of surge cycles per test (only considering those tests at which surge appears), their frequency and the maximum rate of pressure change (see Section 2.3) are also included in Table 1.

All the modified inlet geometries reduce the amount of tests at which surge appears. The effectiveness of a device in reducing surge occurrence 
is correlated with its surge margin improvement (see Fig. 6). However, the surge line of the convergent-divergent nozzle is only slightly better than the one obtained by the tapered duct, since surge occurs $10 \%$ times more for the tapered duct than for the convergent-divergent nozzle.

Even though the tapered duct only reduces by $5 \%$ the number of tests at which surge happens compared to the baseline case, the average number of surge cycles at these experiments is $30 \%$ less than with the straight duct, being (by far) the most effective intake geometry in this particular aspect. The tapered duct also reduces the surge frequency by almost $20 \%$ regarding the reference case. In terms of decreasing the maximum rate of pressure change, the best geometries are the nozzles, with a reduction of about $20 \%$ compared to the case with a straight duct.

\begin{tabular}{|c|c|c|c|c|}
\hline \multirow{2}{*}{ Conf } & \multicolumn{2}{|c|}{ Surgerge } & \multicolumn{2}{|c|}{ Surge Rate of } \\
\hline & & ] [\#] & {$[\mathrm{Hz}]$} & {$[-\mathrm{bar} / \mathrm{s}]$} \\
\hline a) & 43 & 4.8 & 6.5 & 4.1 \\
\hline b) & 41 & 3.3 & 5.3 & 4 \\
\hline c) & 37 & 4.6 & 6.8 & 3.3 \\
\hline d) & 35 & 4.4 & 6.7 & 3.4 \\
\hline
\end{tabular}

Table 1: Summarizing table of transient results

\section{Concluding remarks}

Four different geometries have been assembled into a compressor entry. The studied geometries are a straight duct, a tapered duct, a convergent 
nozzle and a convergent-divergent nozzle. Steady and transient tests have been performed in an engine test bench for each configuration, thus reproducing the actual performance of each set of intake geometry and turbocharger. The experiments are conducted to assess the influence of the intake geometry not only on compression ratio but also on efficiency and noise emissions near surge conditions. The transient tests are particularly relevant because they consist in a sudden pedal release, which reproduces a driver's tip-out maneuver that may lead the compressor into surge.

The standard straight duct presents the worst performance in the surge side of the compressor map. Its surge line is the most restrictive, isentropic efficiency at this zone is the lowest and it is the most likely to enter into surge and produce the maximum harm in driving-like conditions. The tapered duct improves the surge margin and slightly increases the pressure ratio at high mass flow rates as well. It presents an enhanced isentropic efficiency and the number of surge cycles (and surge frequency) is reduced when surge happens due to a sudden pedal release.

The convergent-divergent nozzle shifts the surge line slightly more than the tapered duct, presenting the greatest isentropic efficiency of all the studied geometries at the surge side of the compressor map. Additionally, the performance at the transient tests is improved in terms of surge occurrence and maximum rate of pressure change. Finally, the convergent nozzle behavior is similar to its convergent-divergent counterpart, but it produces the maximum surge margin gain and intake orifice noise is strongly reduced. However, it performs poorly at high mass flow rates, showing a reduced pressure ratio due to the reduced flow effective cross-section at the inducer plane. 
The most promising inlet geometries are therefore the tapered duct and the convergent-divergent nozzle. The limitations of this study should be taken into account when drawing such conclusion. Only intake geometries that are easy to construct have been considered, and they may not be optimized. In addition, only the surge side of the compressor map and an isospeed line $(160 \mathrm{krpm})$ has been measured. These inlet geometries may change the compressor performance at other operating conditions. Moreover, some particular aspects of the impact of the intake geometries cannot be explained without additional information, such as the effect of the distance between the compressor wheel and the tapered duct. To shed more light on the topic, 3-dimensional CFD simulations with the whole compressor and intake geometry would be needed.

\section{Acknowledgements}

Daniel Tarí is partially supported through contract FPI-S2-2015-1095 of Programa de Apoyo para la Investigación y Desarrollo (PAID) of Universitat Politècnica de València.

\section{References}

[1] Galindo J, Serrano JR, Guardiola C, Cervelló C. Surge limit definition in a specific test bench for the characterization of automotive turbochargers. Experimental Thermal and Fluid Science. 2006;30(5):449-462.

[2] Greitzer EM. Surge and rotating stall in axial flow compressors-Part I: Theoretical compression system model. Journal of Engineering for Gas Turbines and Power. 1976;98(2):190-198. 
[3] Huppert MC. Compressor surge; 1965.

[4] Fink D, Cumpsty N, Greitzer E. Surge dynamics in a free-spool centrifugal compressor system. Journal of Turbomachinery. 1992;114(2):321332.

[5] Willems F, De Jager B. Modeling and control of compressor flow instabilities. Control Systems, IEEE. 1999;19(5):8-18.

[6] Epstein A, Ffowcs Williams J, Greitzer E. Active suppression of aerodynamic instabilities in turbomachines. Journal of Propulsion and Power. $1989 ; 5(2): 204-211$.

[7] de Jager B; IEEE. Rotating stall and surge control: A survey. 1995;2:1857-1862.

[8] Gysling DL, Dugundji J, Greitzer E, Epstein A. Dynamic control of centrifugal compressor surge using tailored structures. Journal of Turbomachinery. 1991;113(4):710-722.

[9] Whitfield A, Sutton A, Leonard H. The development of turbocharger compressors with improved surge margin. ImechE C433/063. 1991;p. 9.

[10] Ariga I, Kasai N, Masuda S, Watanabe Y, Watanabe I. The effect of inlet distortion on the performance characteristics of a centrifugal compressor. Journal of Engineering for Gas Turbines and Power. 1983;105(2):223230.

[11] Galindo J, Serrano JR, Margot X, Tiseira A, Schorn N, Kindl H. Potential of flow pre-whirl at the compressor inlet of automotive engine 
turbochargers to enlarge surge margin and overcome packaging limitations. International journal of heat and fluid flow. 2007;28(3):374-387.

[12] Gravdahl JT, Egeland O, Vatland SO. Drive torque actuation in active surge control of centrifugal compressors. Automatica. 2002;38(11):18811893.

[13] Engeda A, Kim Y, Aungier R, Direnzi G. The inlet flow structure of a centrifugal compressor stage and its influence on the compressor performance. Journal of fluids engineering. 2003;125(5):779-785.

[14] Capon G, Morris T. The effect of air inlet system features on automotive turbocharger compressor performance. In: $9^{\text {th }}$ International Conference on Turbochargers and Turbocharging; 2010. .

[15] Baris O, Mendonça F. Automotive Turbocharger Compressor CFD and Extension Towards Incorporating Installation Effects. In: Proceedings of ASME Turbo Expo 2011: Power for Land, Sea and Air. ASME; 2011. p. $2197-2206$.

[16] Pampreen RC. Compressor surge and stall. Concepts Eti Vermont; 1993.

[17] Serrano JR, Margot X, Tiseira A, García-Cuevas LM. Optimization of the inlet air line of an automotive turbocharger. International Journal of Engine Research. 2013;14(1):92-104.

[18] Lang R. Contribución a la Mejora del Margen de Bombeo en Compresores Centrífugos de Sobrealimentación. Uni- 
versitat Politècnica de València; 2011. Available from: http://hdl . handle.net/10251/12331.

[19] Evans D, Ward A. Minimizing Turbocharger Whoosh Noise for Diesel Powertrains. SAE Technical Paper. 2005;2005-01-2485.

[20] Teng C, Homco S. Investigation of Compressor Whoosh Noise in Automotive Turbochargers. SAE Int J of Passeng Cars-Mech Syst. 2009;2(1):1345-1351.

[21] Broatch A, Galindo J, Navarro R, García-Tíscar J, Daglish A, Sharma RK. Simulations and measurements of automotive turbocharger compressor whoosh noise. Engineering Applications of Computational Fluid Mechanics. 2015;.

[22] Broatch A, Galindo J, Navarro R, García-Tíscar J. Methodology for experimental validation of a CFD model for predicting noise generation in centrifugal compressors. International Journal of Heat and Fluid Flow. 2014;50:134-144.

[23] Karim A, Miazgowicz K, Lizotte B, Zouani A. Computational AeroAcoustics Simulation of Compressor Whoosh Noise in Automotive Turbochargers. SAE Technical Paper. 2013;2013-01-1880.

[24] Luján J, Bermúdez V, Serrano JR, Cervelló C. Test bench for turbocharger groups characterization. SAE Technical Paper. 2002;2002-010163. 
[25] Jenny E. Uber Instationnäire Vorgänge in Radialverdichtern Insbesondere in Aufladegruppen Von Verbrennungmotoren. Schweiz Bauzeitung, Bd;79:802-817.

[26] Galindo J, Climent H, Guardiola C, Tiseira A. On the effect of pulsating flow on surge margin of small centrifugal compressors for automotive engines. Experimental Thermal and Fluid Science. 2009;33(8):11631171.

[27] Raitor T, Neise W. Sound generation in centrifugal compressors. Journal of Sound and Vibration. 2008;314:738-756.

[28] Guillou E, Gancedo M, Gutmark E, Mohamed A. PIV investigation of the flow induced by a passive surge control method in a radial compressor. Experiments in fluids. 2012;53(3):619-635.

[29] Torregrosa AJ, Broatch A, Navarro R, García-Tíscar J. Acoustic characterization of automotive turbocompressors. International Journal of Engine Research;.

[30] Galindo J, Tiseira A, Arnau FJ, Lang R. On-Engine Measurement of Turbocharger Surge Limit. Experimental Techniques. 2013;37(1):47-54.

[31] Galindo J, Arnau F, Tiseira A, Lang R, Lahjaily H, Gimenes T. Measurement and Modeling of Compressor Surge on Engine Test Bench for Different Intake Line Configurations. SAE Technical Paper. 2011;201101-0370.

[32] Leufven O, Eriksson L. Time to surge concept and surge control for acceleration performance. In: Proceedings of the $17^{\text {th }}$ IFAC World 
Congress, 2008. International Federation of Automatic Control (IFAC); 2008. p. 2063-2068.

[33] Wang CH, Wang CC. Design and Implementation of Intelligent Surge Controller for Modern Turbo Charged Automobiles. International Journal of Fuzzy Systems. 2014;16(2):222-232.

[34] Desantes J, Luján JM, Plá B, Soler J. Potential of using a nozzle at the compressor inlet of a high-speed direct-injection diesel engine. Proceedings of the Institution of Mechanical Engineers, Part D: Journal of Automobile Engineering. 2011;225(2):178-189. 